\title{
Acoustic study of the influence of climate change on the propagation of noise generated by industrial units in real-time: by an industrial zone in Algeria
}

\author{
Arbaoui Iliace', Tadjeddine Ali Abderrazak ${ }^{2}$, Hamiani Hichem ${ }^{3}$, Hamou Ahmed ${ }^{4}$ \\ ${ }^{1,4}$ LESEM Laboratory, Oran1 University, Algeria \\ ${ }^{2}$ SCAMRE Laboratory, National Polytechnic School of Oran (ENPO-MA), Algeria \\ ${ }^{3}$ LAAS Laboratory, National Polytechnic School of Oran (ENPO-MA), Algeria
}

\section{Article Info}

Article history:

Received Sep 22, 2020

Revised Mar 31, 2021

Accepted May 7, 2021

\section{Keywords:}

Climate Change

COD-TYMPAN

Industrial, Noise

Noise Pollution

Real Time

\begin{abstract}
The industrial revolution in the field of gas and oil treatment that has known the Oran region-Algeria-has participated in the production and propagation of noise pollution and loud noises on the environment and around the places residential, for this, a multitude of noises are now part of our daily life. This contribution concerns the propagation of noise pollution in the industrial environment and the effects caused by atmospheric pollution which has a great influence on the phenomenon of planetary climate change and on meteorological parameters, the latter having a great influence on the propagation of noise. Our study is part of the objective of evaluating the noise levels emitted by gas installations in the industrial zone of ArzewOran, and of seeing the effects of the variation of meteorological parameters on the propagation of noise. To do this, we have adopted a precise in-situ methodology. Subsequently, for the processing of the measurement results, we opted for the COD-TYMPAN software in real-time as a calculation tool to interpret our results.
\end{abstract}

This is an open access article under the CC BY-SA license.

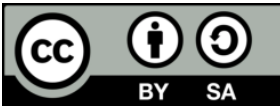

Corresponding Author:

Arbaoui Iliace

LESEM Laboratory

Oran1 University, Algeria

Email: arbaoui.iliace@gmail.com

\section{INTRODUCTION}

The industrial revolution has not only disrupted the economies of developed countries but also their environment. Noise pollutants have been unknown for 50 years ago, now they are part of our daily life, especially in residential areas near industrial areas highly polluted by noise. For this, the current world suffers a lot from industrial activities which generate atmospheric pollution and especially emissions of greenhouse gases, the latter mainly contributing to climate change.

Noise is the second environmental factor in terms of health damage (WHO) [1], its dangerousness depends on the nature of the source that generates it (transport, industry). Algerian industry is an essential segment of the country's economic development [2], but generates significant pollution of our environment by different types of pollution (atmospheric [3]-[6], solid [7]-[13], marine [13]-[17]. Among these types of pollution, noise pollution is quite rare in scientific circles.

Today, the concern about noise pollution is considerable importance, especially in industrial environment where there is a large amount of machinery and equipment [18]. Several research studies have been carried out to address the problem of noise in urban and industrial environments [17]-[30]. Recent studies have shown that noise from industrial sources is more annoying than transporting noise (at equivalent 
noise levels) [31]. This is mainly due to the specific characteristics of the industrial noise source, which emits different noises with dangerous characteristics (tonal, impulsive) [32]-[34].

These noises therefore directly affect workers at industrial sites, and indirectly affect the residents in the vicinity of these sites. Its dangerousness depends on the one hand on its own characteristics (its intensity, its frequency, its acoustic pressure, its duration and especially its level of exposure). On the other hand, it depends on the environment in which the meteorological parameters propagate, which plays a very important role in the acoustic propagation of noise (the speed of noise increases with the increase in air temperature).

Actually, the concern about climate change is gaining considerable importance, especially in an industrial environment where there is a very high rate of pollution (atmospheric, marine or noise). The industrial zone of Arzew (Oran--Algeria) is worldwide ranked among the tops twenty industrial zones [35][36] in the field of processing and exploitation of a gas and oil. However, on the environmental level, the complexes in the industrial area of Arzew generate a lot of pollution (atmospheric, marine and noise).

In our study, we were interested in the effect of climate change and meteorological parameters (temperature, humidity, wind speed and direction) on the propagation of noise pollution generated by the complexes of the industrial area.

\section{MATERIALS AND METHODS}

\subsection{Material used:}

The sound level meter we used is an integrating sound level meter (CLASS 2/UMERICEST-107) type II. It includes a special amplifier; a microphone and a voltage divider, which allow reaching an attenuation of electric signals, for stay in the amplifier linearity, range (50 to $80 \mathrm{~dB}$ ) whatever the sound level. The Attenuator function can also allow the display of an easy-to-read measurement. It also includes the weighted filter, in particular the weighting filter A (it is a detection and reading device), that contains another amplifier and rectifier. So that the signal displayed is proportional to the effective noise pressure.

The information captured in the field by the acquisition and allocation of data in real-time [37]-[39], each second is measured simultaneously, and they are centralized on a central unit. This allows us to order and analyze our overall system with all the noise levels in $\mathrm{dB}(\mathrm{A})[40]$.

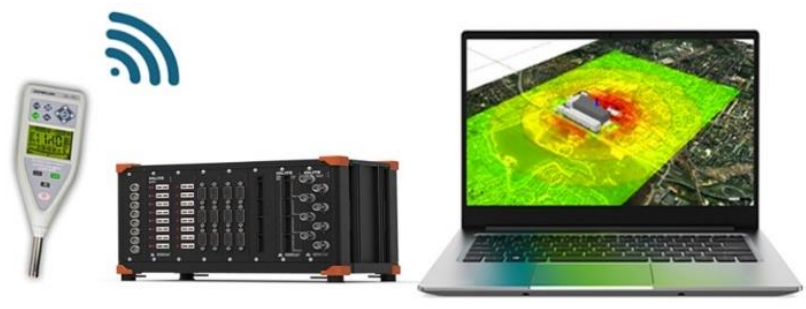

Figure 1. The system of measurement and simulation used

This study focuses on the environmental impact in terms of climate change on the propagation of noise pollution generated by Arzew industrial units.

Noise is defined as a vibration that propagates through the air. It causes an auditory sensation, which can be pleasant or become unpleasant, even dangerous if its level is excessive. It is measured in decibels $(\mathrm{dB})$ and is characterized by [36]-[38]:

- Sound intensity: above 60 decibels $(\mathrm{dB})$, there is a risk for hearing;

- Low or high frequency: high noise is more dangerous than low frequency;

- Sound pressure, which quantifies the amplitude of a sound;

- Duration: the noise dose is proportional to the exposure time.

\subsection{Method}

1 - Input data

2 - Data processing and adjusting

3 - Using modelling

4 - Noise maps production

The Figure 2 presented the Data Acquisition System DAS. 


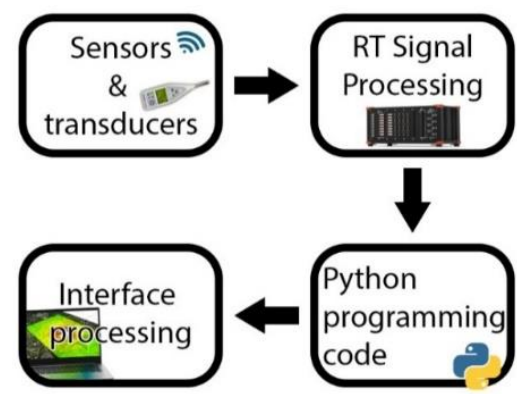

Figure 2. Block Diagram of a Data Acquisition System

\subsection{Phenomena involved in acoustic propagation in an outdoor environment}

We present the phenomena involved in linear acoustic propagation in an external environment. The determination of the sound pressure field depends on several parameters related to the characteristics of the propagation medium (atmosphere), to the boundary conditions (soil, diffraction), to the physical characteristics of the source as well as to the geometric configuration (position of the source and the receiver, land transport infrastructure) [40]-[41].

The relation of the pressure level $\boldsymbol{L p}$ calculated by:

$$
\text { Lp }=\text { Lw - Attdiv - Attabs - Attdif - Attground - WeatherAt }
$$

Where:

The pressure level $\boldsymbol{L} \boldsymbol{p}$ calculated by considering the sum of the attenuations due to the geometric divergence Attdiv, the absorption of the atmosphere and the materials Attabs, the diffraction by the obstacles Attdif, the ground effect Attground and attenuation due to meteorological effects Weather At, $L w$ is the sound power level of the sound source.

The relationship of the speed of sound defined by:

$V S=\sqrt{\boldsymbol{\gamma} \cdot \boldsymbol{R} \cdot \boldsymbol{T}}(\mathrm{m} / \mathrm{s})$

Where:

$\gamma$ : (Gamma) the adiabatic constant.

$\boldsymbol{R}$ : The molar gas constant $[\mathrm{J} . \mathrm{kg}-1 . \mathrm{K}-1]$

$\boldsymbol{T}$ : The absolute temperature $\mathrm{K}$.

In standards condition: $R_{\text {air }}=287 \mathrm{~J} . \mathrm{kg}^{-1} . \mathrm{K}^{-1}$ and $\boldsymbol{\gamma}=\mathbf{1 . 4}$, So $\mathrm{Vs}=20.04 \sqrt{\mathrm{T}}$

We notice that the speed of sound in the area and proportionally with the square root of the area temperature. The climate change causes a significant increase in ambient temperature and therefore affects the propagation of noise.

To see the effect of the temperature increases on the propagation of noise generated by Arzew's industrial units, we opted for the following approach:

A series of measurements made at the noise sources (inside the GP1/Z, GNL1Z and GNL2 complexes).

We set out to map the noise of the study area using the COD-TYMPAN simulation software,

Knowing that to see the effect of the increase in temperature we have each time varied the temperature between $T=25^{\circ} \mathrm{C}, \mathrm{T}>25^{\circ} \mathrm{C}, \mathrm{T}<25^{\circ} \mathrm{C}$

The management of ambient noise has defined various global indicators, in particular [41]-[42]:

- Lday corresponds to the average noise level representative of a day (LAeq (7am-7pm)), determined over a year. It is an indicator of noise associated with annoyance during the daily period.

- Levening corresponds to the average noise level representative of an evening (LAeq (19h-23h)), determined over a year. It is an indicator of noise associated with annoyance in the evening.

- Lnight corresponds to the average annual noise level representative of a night (LAeq (11pm-7am)). He makes

- a noise indicator associated with sleep disturbances. 
- The weighted indicator Lden (day-evening-night) represents the average annual level over 24 hours evaluated from the average levels of the day (7am-7pm), evening (7pm-11pm) and night (11pm-7am). In its calculation, the average evening and night levels increased by 5 and $10 \mathrm{~dB}$ (A) respectively.

In other words, this noise indicator is associated with the overall acoustic annoyance associated with long-term noise exposure and takes into account that noise experienced in the evening and at night experienced as more annoying. It used in particular for the establishment of strategic noise maps. It calculated according to the formula:

$$
L_{D E N}=10 \log \left(\frac{1}{24}\right)\left[12 * 10^{\frac{L A_{e q} 7-19}{10}}+8 * 10^{\frac{L A_{e q} 23-7}{10}}+4 * 10^{\frac{L A_{e q} 19-23}{10}}\right]
$$

\section{RESULTS AND DISCUSSION}

In the first part of our work, we have carried out of noise measurements in real-time in order to evaluate the noise pollution in the industrial units GP1/Z, GNL1 and GNL2.

Tables 1, 2, 3 and 4 represent the noise levels recorded in real-time in the three complex zones GP1/Z, GNL1 and GNL2. Table 1 shows the turbocharger train noise levels recorded in the GP1/Z complex zone. Table 2 shows the compressors noise levels recorded in the complex zone GNL1. Table 3 shows the pic-train noise levels recorded in the complex zone GNL1. Table 4 shows the pic-train noise levels recorded in the complex zone GNL2.

Table.1. Noise levels recorded in the GP1/Z complex

\begin{tabular}{cc}
\multicolumn{2}{c}{ zone } \\
\hline Noise source & Noise level measured in dB (A) \\
\hline Turbocharger train 100 & 95,0 \\
Turbocharger train 200 & 94.5 \\
Turbocharger train 300 & 95,0 \\
Moto compressor train 600 & 91,0 \\
Moto compressor train 700 & 90,0 \\
\hline
\end{tabular}

Table.3. Noise levels recorded in the GNL1 complex

\begin{tabular}{cc}
\multicolumn{2}{c}{ zone } \\
\hline Noise source & Noise level measured in dB (A) \\
\hline Pic Train 100 & $95 \mathrm{~dB}$ \\
Pic Train 200 & $95 \mathrm{~dB}$ \\
Pic Train 300 & $95 \mathrm{~dB}$ \\
Pic Train 400 & $95 \mathrm{~dB}$ \\
Pic Train 500 & $95 \mathrm{~dB}$ \\
\hline
\end{tabular}

Table.2. Noise levels recorded in the GNL1 complex zone

\begin{tabular}{cc}
\hline Noise source & Noise level measured in dB (A) \\
\hline Compressor 1 Train 100 & $95 \mathrm{~dB}$ \\
Compressor 2 Train 200 & $95 \mathrm{~dB}$ \\
Compressor 3 Train 300 & $95 \mathrm{~dB}$ \\
Compressor 4 Train 400 & $95 \mathrm{~dB}$ \\
Compressor 5 Train 500 & $95 \mathrm{~dB}$ \\
\hline
\end{tabular}

Table.4. Noise levels recorded in the GNL2complex zone

\begin{tabular}{lc}
\hline Noise source & Noise level measured in dB (A) \\
\hline Pic Train 100 & $115 \mathrm{~dB}$ \\
Pic Train 200 & $95 \mathrm{~dB}$ \\
Pic Train 300 & $95 \mathrm{~dB}$ \\
Pic Train 400 & $95 \mathrm{~dB}$ \\
\hline
\end{tabular}

According to the results of noise recording in GP1/Z, GNL1 and GNL2 complex zone, we notice that the noise pollution in the three complexes is higher; Tables 1,2,3, and 4 represent the principal factors that cause noise pollution in the industrial area are rotors of machines such as compressors and turbines.

The noise level results showed that the noise levels were between 95 and $115 \mathrm{~dB}$ (A). To determine the effect of variations in meteorological parameters on the propagation of noise, we studied two scenarios:

1. In the first scenario: this involves setting the simulator on the ambient temperature $\mathrm{T}=25^{\circ} \mathrm{C}$;

2. In the second scenario: it consists in varying the meteorological parameters in the following ways $T=25^{\circ} \mathrm{C}, T>25^{\circ} \mathrm{C}, T<25^{\circ} \mathrm{C}$, the effect of temperature on noise propagation.

In the second part of this work, we have evaluated noise pollution by noise mapping generated inside the industrial area of Arzew: GP1/Z, GNL1 and GNL2 complex zone.

\subsection{Complex of GP1/Z}

In figures 3, 4 and 5 below, we have represented the different simulation results found in the GP1/Z complex according to the two scenarios developed under the meteorological conditions; temperature variation $\mathrm{T}>25^{\circ} \mathrm{C}, \mathrm{T}=25^{\circ} \mathrm{C}$ or $\mathrm{T}<25^{\circ} \mathrm{C}$, with humidity $=70 \%$, and wind speed $=20 \mathrm{~km} / \mathrm{h}$.

Figures 3 shows the mapping generated of the noise by the GP1/Z complex zone under meteorological conditions, temperature $\mathrm{T}>25^{\circ} \mathrm{C}$. 
Figures 3, 4, and 5 represent the noise mapping generated by the impact of temperature variation on noise propagation in GP1/Z complex. The red dots represent the sources of noise where its value is great. More we will move away from noise sources, more noise pollution dissipate.

Figures 4 shows the mapping generated of the noise by the GP1/Z complex zone under meteorological conditions, temperature $\mathrm{T}=25{ }^{\circ} \mathrm{C}$. Figures 5 shows the mapping generated of the noise by the GP1/Z complex zone under meteorological conditions, temperature $\mathrm{T}<25^{\circ} \mathrm{C}$.

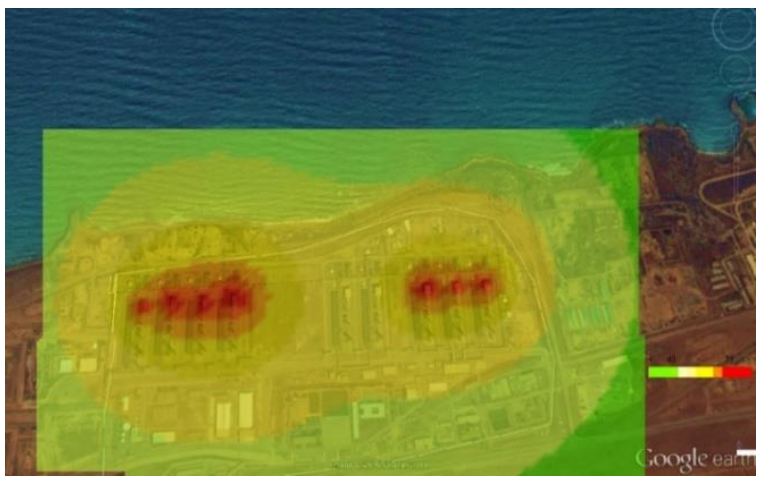

Figure 3. Noise mapping generated by the GP1/Z complex under meteorological conditions $\left(\mathrm{T}>25^{\circ} \mathrm{C}\right)$

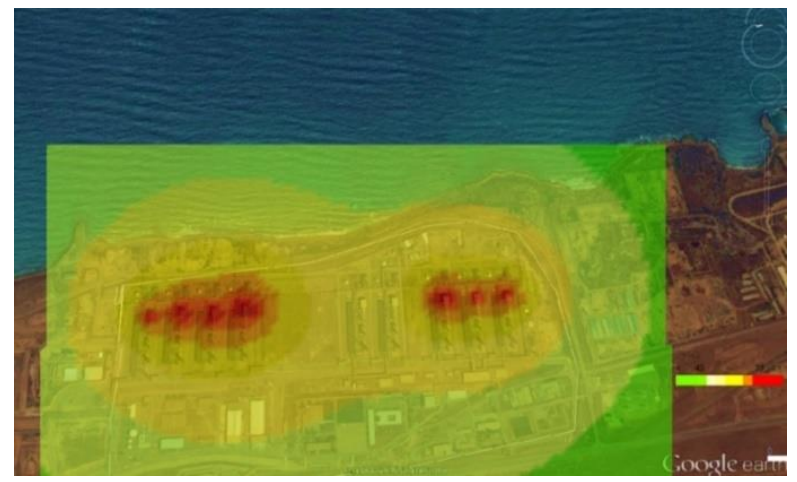

Figure 4. Noise mapping generated by the GP1/Z complex under meteorological conditions $\left(\mathrm{T}=25^{\circ} \mathrm{C}\right)$

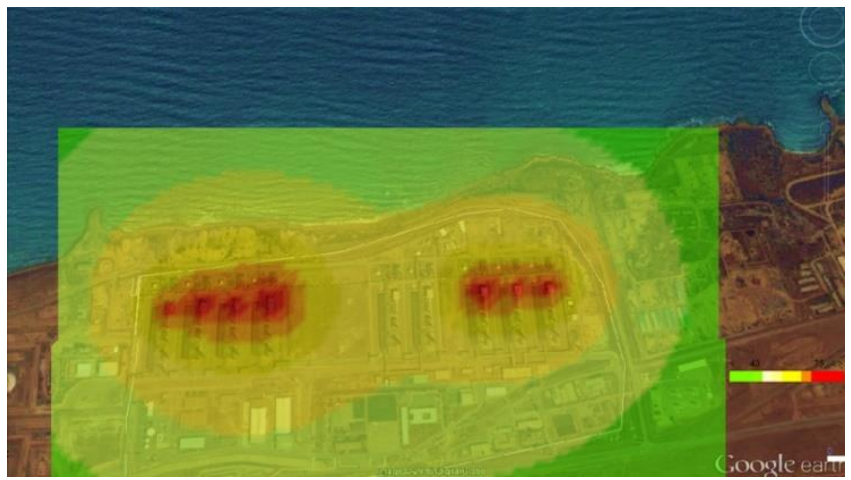

Figure 5. Noise mapping generated by the GP1/Z complex under meteorological conditions $\left(\mathrm{T}<25^{\circ} \mathrm{C}\right)$

\subsection{Complexes of GNL1 and GNL2}

The Figures 6, 7 and 8 below, represent noise mapping generated for the two complex zone factories GNL1 and GNL2 under the meteorological conditions; temperature variation $\mathrm{T}>25{ }^{\circ} \mathrm{C}, \mathrm{T}=25^{\circ} \mathrm{C}$ or $\mathrm{T}<25^{\circ} \mathrm{C}$, with humidity $=70 \%$, and wind speed $=19 \mathrm{~km} / \mathrm{h}$.

Figures 6 shows the mapping generated of the noise by the GNL1 and GNL2 complex zone under meteorological conditions, temperature $\mathrm{T}>25{ }^{\circ} \mathrm{C}$. Figures 7 shows the mapping generated of the noise by the GNL1 and GNL2 complex zone under meteorological conditions, temperature $\mathrm{T}>25^{\circ} \mathrm{C}$. Figures 8 shows the mapping generated of the noise by the GNL1 and GNL2 complex zone under meteorological conditions, temperature $\mathrm{T}<25^{\circ} \mathrm{C}$.

Figures 6, 7, and 8 represent the noise mapping generated by the impact of meteorological conditions on noise propagation in GNL1 and GNL2 complexes zone. The red dots represent the sources of noise where its value is great. More we will move away from noise sources, more noise pollution dissipate.

Figures 3-8 above represent a noise map on the two complex zones GP1 / Z, GNL1 and GNL2. It is remarkable that the places where the turbines and compressors are installed are the noisiest; but as one moves away from the center of the noisy space, the noise gradually slows down.

According to the simulation results found, it can be seen that meteorological parameters play a very important role in the phenomenon of acoustic propagation of noise pollution. When the parameters change, we see that the noise propagation surface increases and can reach the residential areas next to the industrial zone of Arzew. 


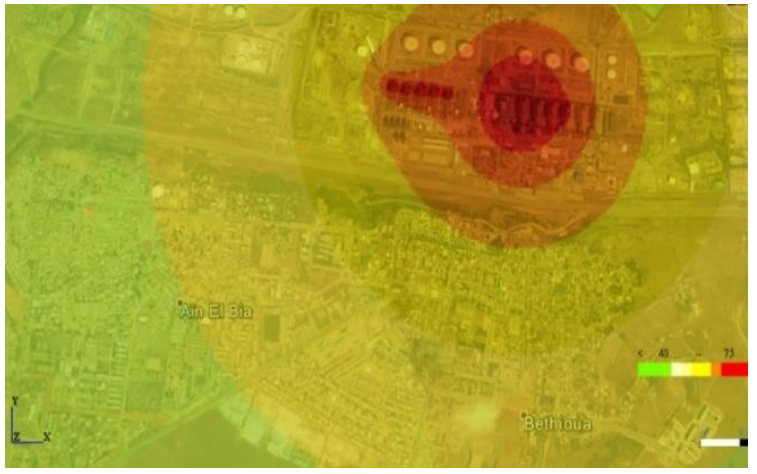

Figure 6. Noise mapping generated by the GNL1 and GNL2 complexes under meteorological conditions $\left(\mathrm{T}>25^{\circ} \mathrm{C}\right)$

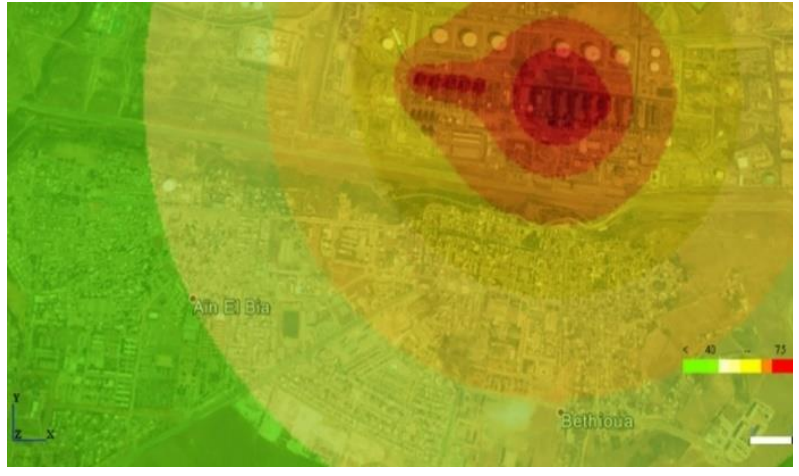

Figure 7. Noise mapping generated by the GNL1 and GNL2 complexes under meteorological conditions ( $\mathrm{T}$ $=25{ }^{\circ} \mathrm{C}$ )

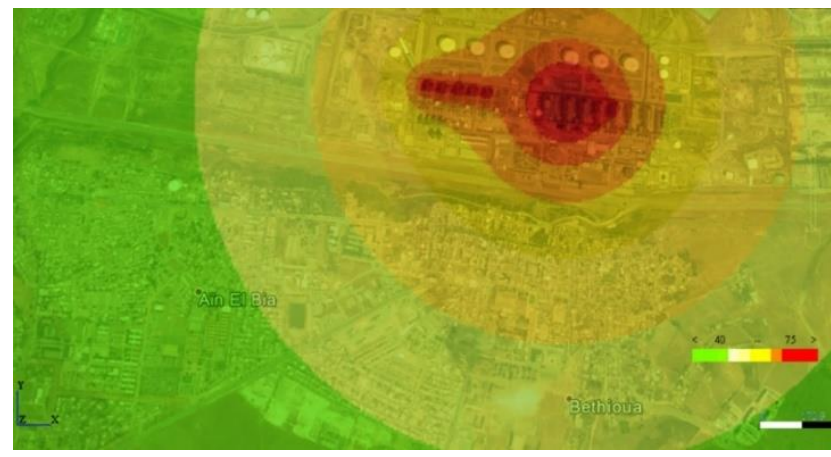

Figure 8. Noise mapping generated by the GNL1 and GNL2 complexes under meteorological conditions (T $\left.<25^{\circ} \mathrm{C}\right)$

\section{CONCLUSION}

From the work we have done, we can see that: a) The propagation of noise is directly linked to the modification of meteorological parameters due to the phenomenon of climate change such as: temperature; or we have observed a wide diffusion that when the temperature is above $25^{\circ} \mathrm{C}$, this diffusion can cause a health risk on the one hand for the workers of these complexes and on the other hand for the neighboring residential areas (Ain-El Bia and Bethioua). We observed subsequently that the noise propagation is reduced when the temperature is lower than $25^{\circ} \mathrm{C}$, which confirms the hypothesis explained. b) The recorded noise levels are higher in the three complexes (plant) GNL1, GNL2, and GP1/Z, whose noise limit is $70 \mathrm{~dB}$ recommended by Algerian regulations. c)The analysis of the noise mapping allowed us to improve the study of noise in the Arzew area by obtaining robust results on noise pollution.

Finally, from the results we obtained, we show that our operator includes two steps, data monitoring, and processing of this data in real-time. This concept implemented through programming and gateways adapting to this study. The efficiency of this system is much more cost-effective as it will also reduce measurement errors and allow us to analyze the data collected on-site in real-time.

\section{REFERENCES}

[1] Report of the World Health Organization, page 1, 2011.

[2] I. Arbaoui, A. Hamou, H. Abderrahim, A. Tayeb and M. R. Chellali, "Inter-comparison of noise pollution in Oran (Algeria): Urban and industrial areas," Journal of Materials and Environmental Sciences, Vol. 9, No. 1, pp. 1-10, 2018, DOI: 10.26872/jmes.2018.9.1.1.

[3] H. Abderrahim and A. Hamou, "Preliminary properties of Saharan aerosol over tamanrasset (Algeria)," J. Mater. Environ. Sci. vol. 5, no. 3, pp. 865-872, 2014.

[4] A. Tayeb, A. Hamou, S. Debbah, "Modelisation of Atmospheric Pollution to Green House Gase CO2 of Arzew Industrial Pole," JSM Environmental Science \& Ecology, vol. 3, no. 1, 1015, 2015. 
[5] A. Tayeb, A. Hamou, S. Debbah, "Modelization of Atmospheric Pollution to Green House GaseNOx of Arzew Industrial Pole," JSM. Environ. Sci. Ecolo., vol. 3, no. 2, 1021, 2015.

[6] Abderrahim H, Chellali MR and Hamou A., "Forecasting PM10 in Algiers: efficacy of multilayer perceptron networks," Environ Sci Pollut Res Int. vol. 23, no. 2, pp. 1634-1641, 2016. DOI: 10.1007/s11356-015-5406-6.

[7] B. Bouhadiba, A. Hamou, M. Hadjel, Y. G. Kehila and Matejka, "New schemes of Municipal Solid Waste Management for the wilaya of Oran, Algeria," Iran. J. Environ. Healt. Sci. Engine., 12, 2014.

[8] Arbaoui. Iliace, Hamou. Ahmed, Tadjeddine Ali Abderrezak, Harrouz Abdelkader and Benoudjafer Cherif, "Acoustic Study of Noise Generated by Arzew's Industrial Units in Limited Batteries", Algerian Journal of Renewable Energy and Sustainable Development, vol. 2, pp. 115-125, January 2021.

[9] Julien Morel, Catherine Marquis-Favre, Stéphanie Viollon, Marion Alayrac, " Predictive models of annoyance in a situation of multiple exposure to industrial noise (in French)," 10ème Congrès Français d'Acoustique, Apr 2010, Lyon, France.

[10] Sabri Benferhat, "Simulation of intracellular traffic conditions of a wireless network in the middle industrial by a composite propagation model (in French)," Réseaux et télécommunications [cs.NI]. Université Blaise PascalClermont-Ferrand II, 2009.

[11] N. Ramdani, Y. Al-Douri and A. Hamou, "Study of the biodegradation and fertility of the co-composting produced from sewage sludge and green waste and its effects on the speciation of heavy metals," J. Mater. Environ. Sci. vol. 6, no. 5, pp. 1310-1320, 2015.

[12] N. Ramdani, A. Hamou, A. Lousdad, Y and Al-Douri, "Physicochemical characterization of sewage sludge and green waste for agricultural utilization," Environ. Techno. vol. 36, no. 12, pp. 1594-1604, 2015.

[13] A. Tayeb, M.R. Chellali, A. Hamou and S. Debbah, "Impact of urban and industrial effluents on the coastal marine environment in Oran, Algeria," Marin. Pollu. Bull., vol. 98, No. 1-2, pp. 281-288, 2015.

[14] Basorun, Joseph Omoniyi, Olamiju and Isaac Oluwadare, "Environmental Pollution and Refinery Operations in an Oil Producing Region of Nigeria: A Focus on Warri Petrochemical," IOSR Journal of Environmental Science, Toxicology and foodTechnology (IOSR-JESTFT). vol. 2, no. 6, pp. 18-23, 2013.

[15] TJ. Schultz, "Synthesis of social surveys on noise annoyance," J. Acoust. Soc. Am., Vol. 64, no. 2, pp. 377-405, 1978.

[16] A. A. Saadu, R.O. Onyeonwu, E.O. Ayorinde and F.O. Ogisi, "Community attitudinal noise survey and analysis of eight Nigeriancities," Appl. Acoust., vol. 49, no. 1, pp. 49-69, 1996.

[17] G. Belojecic, B. Jakovljecic, O. Aleksic, "Subjective reactions to traffic noise with regard to some personality traits," Environment International, vol. 23, no. 2, pp. 221-226, 1997, DOI: 10.1016/S0160-4120(97)00008-1

[18] W. H. K. Lam and M.L. Tam, "Reliabilityanalysis of traffic noise estimates in Hong Kong," Transportation Research Part D: Transport and Environment, vol. 3, no. 4, pp. 239-248, 1998, DOI: 10.1016/S13619209(98)00002-9.

[19] M. Arana and A. Garcia, A social survey on the effects of environmental noise on the residents of Pamplona, Spain. Applied Acoustics, vol. 53, no. 4, pp. 245-253, 1998, DOI: 10.1016/S0003-682X(97)00067-4.

[20] C. Maschke, "Preventive medical limits for chronic traffic noise exposure," Acustica, vol. 85, pp. 444-448, 1999.

[21] P. H. T. Zannin, F. B. Diniz, A. Calixto and W. Barbosa, "Environmental noise pollution in residential areas of the city of Curitiba," Acustica, 87, 625-8, 2001.

[22] P. H. T. Zannin, F. B. Diniz, A. Calixto and W. Barbosa, "Environmental noise pollution in the city of Curitiba," Brazil. Appl. Acoust., vol. 63, pp. 351-8, 2002.

[23] J. M. B. Morillas, R. V. G. Gómez, V. G. Escobar, J. A. M Sierra, C. T. Vidal and L. A. Bueno, "Presentation of a survey for social studies on the impact of urban noise," Rev. Acust., vol. 33, pp. 27-31, 2002.

[24] P. H. T. Zannin, B. Szeremetta, "Evaluation of noise pollution in the Botanical Gardens of Curitiba, Paraná, Brazil," Cad. Saude. Publica., vol. 19, no. 2, pp. 683-686, 2003, DOI: 10.1590/s0102-311x2003000200037.

[25] E. C. Paz, A. M. C. Ferreira, P. H. T. Zannin, "Comparative study of the perception of urban noise," Rev. Saude. Publica. (J Public Health), vol. 39, no. 3, pp. 467-72, 2005, DOI: 10.1590/S0034-89102005000300019.

[26] P. H. T. Zannin, D. Q. Sant'Ana, "Noise mapping at different stages of a freeway redevelopment project - A case study in Brazil," Applied Acoustics, vol. 72, no. 8, 479-86, 2011, DOI: 10.1016/j.apacoust.2010.09.014.

[27] I. C. M. Guedes, S. R Bertoli and P. H. T. Zannin, "Influence of urbanshapes on environmental noise: a case study in Aracaju Brazil," Science of The Total Environment, Vol. 412-413, pp. 66-76, 2011, DOI: 10.1016/j.scitotenv.2011.10.018.

[28] P. H. T. Zannin, M. S. Engel MS, P. E. K. Fiedlera and F. Bunn, "Characterization of environmental noise Based on noise," Cities, Vol. 31, Pages 317-327 2017, 2013, DOI: 10.1016/j.cities.2012.09.008.

[29] E. Atmaca, I. Peker and A. Altin, "Industrial Noise and Its Effects on Humans," Polish Journal of Environmental Studies, vol. 14, no. 6, pp. 721-726, 2005.

[30] Mario Rossi, Homme et son, Audio, PPUR presses polytechniques, PPUR Collection : Electricité, pp. 153, 2007.

[31] " health impacts of noise, French environmental health safety agency (in French),", 94704 Maisons-Alfort Cedex, Novembre 2004.

[32] DVISOR: Michel Roger, "Analytical modeling of tonal rotor/stator interaction noise using the modal connection technique (in French)," thèse doctorat, janvier 2017

[33] Guillaume LE NOST, Thèse de doctorat, "Contribution to the study of the environmental noise impact of industrial sites : a perceptual typology of noise source (in French)," Année 2007.

[34] Iliace Arbaoui, Ahmed Hamou, Sarra Hennane, Nasreddine Sayad, Iliyes Kelkoul, Ali Abderrazak Tadjeddine, Abdelhakem Belaghit, Yacine Boujemaa and Assia Arbaoui, "Comparative Study of the Noise Generated by 
Rotating Machines in Industrial Area of Arzew (Algeria): A Case Study in GP1/Z Plant,” Der Pharma Chemica, vol. 10, no. 5, 2018

[35] I. Arbaoui, A. Hamou, H. Abderrahim, A. Tayeb, N. Sayad and A. Arbaoui, "Comparative study of the noise generated by the moto-compressor and thatgenerated by the turbo-compressor," Journal of Fundamental and Applied Sciences, vol. 10, no. 1, pp. 201-215, 2018, DOI: 10.4314/jfas.v10i1.15.

[36] Ali. A. Tadjeddine, A. Chaker, M. Khiat, L. Abdelmalek and N. Khalfalah, "A contribution to the control of voltage and power of the interconnection between two decentralized electrical grids with an optimal localization of the SVC devices in real-time", International Journal of Power Electronics and Drive System (IJPEDS), Vol. 10, No. 1, pp.170-177, 2019, DOI: 10.11591/ijpeds.v10.i1.pp170-177.

[37] Ali. A. Tadjeddine, I. Arbaoui, H. Hamiani and A. Chaker, "Optimal distribution of power under stress on power grid in real-time by reactive compensation-management and development in balance," International Journal of Power Electronics and Drive System (IJPEDS), Vol. 11, No. 2. pp. 685-691, 2020, DOI: 10.11591/ijpeds.v11.i2.pp685-691.

[38] Gonzalez A., Olazagoitan J., and J. Vinolas, "A Low Cost Data acquisition System for Automobile Dynamic Applictions," Sensors, pp. 1-20, 2018, DOI: 10.3390/s18020366.

[39] Teli Saraswati and C. Mani, "Smart Real-time Embedded Arduino based Data Acquisition System," International Journal of Research in Engineering and Technology, pp258-262, 2015.

[40] Pratiksha Sarma, Tulshi Bezboruah, "A Real-Time Data Acquisition System for Monitoring Sensor Data", International Journal of Computer Sciences and Engineering, vol. 6, no. 6, 2018.

[41] Richard Croce and Eric Gaucher, " The environmental noise prevention plan (in French)," Rapport de mission acoustique, PPBE du Grand Troyes, Rapport N 4039-9626.

[42] Jonathan Terroir, "Literature study on the dangerousness of impulse noises (in French)," [Rapport de recherche] Notes scientifiques et techniques NS 365, Institut National de Recherche et de Sécurité (INRS). pp.59, 2020. 